\title{
Simple method for visual detection of glutathione $S$-transferase activity and inhibition using cysteamine-capped gold nanoparticles as colorimetric probes
}

\author{
Shan Ren ${ }^{1} \cdot$ Fulin $\mathrm{Zhou}^{1} \cdot$ Chunli Xu$^{1} \cdot$ Baoxin $^{\mathrm{Li}^{1}}$ \\ Published online: 20 November 2015 \\ (C) The Author(s) 2015. This article is published with open access at SpringerLink.com
}

\begin{abstract}
An operationally simple colorimetric method for measuring glutathione $S$-transferase (GST) activity was developed using cysteamine-capped gold nanoparticles (AuNPs) in this work. This method was based that GST can catalyze the reaction of 1-chloro-2,4-dinitrobenzene (CDNB) and glutathione (GSH) to produce a conjugate (CDNB-SG). GSH could induce the aggregation of AuNPs, whereas the conjugate could not induce the aggregation of AuNPs. Thus, GST activity can be facilely assayed with the naked eye or a simple colorimetric reader. The convenient and simple colorimetric response of the assay makes them an attractive approach for drug-screening application.
\end{abstract}

Keywords Glutathione $S$-transferase · Colorimetric method . Gold nanoparticles · Inhibition

\section{Introduction}

Glutathione $S$-transferases (GSTs) constitute a family of detoxification enzymes that catalyze the conjugation of glutathione (GSH) with a variety of hydrophobic compounds, including drugs and their metabolites, to yield water-soluble derivatives that are excreted in urine or bile. GSTs are involved in multiple biological functions, including xenobiotic detoxification, clearance of oxidative stress products, protein transport, modulation of cell proliferation, and induction of the

Baoxin Li

libaoxin@snnu.edu.cn

1 Key Laboratory of Analytical Chemistry for Life Science of Shaanxi Province, School of Chemistry and Chemical Engineering, Shaanxi Normal University, Xi'an 710062, China apoptosis signaling pathway [1]. Moreover, GST isozymes (Alpha, $\mathrm{Mu}$, and $\mathrm{Pi}$ ) are frequently over-expressed in neoplastic tissues and have been considered as an important marker for a number of tumors such as lung, ovarian, breast, and gastric carcinoma [2, 3]. The assay of GST activity is of high importance for the development of efficient therapeutics and the screening of new anticancer drugs. To date, 1-chloro-2,4dinitrobenzene (CDNB), a ultraviolet chromogenic substrate, is the most prevalent probe for the assay of GST activity [4]. However, the chromogenic probe faces some obvious flaws like short absorption wavelength ( $340 \mathrm{~nm}$ ), high background, and low sensitivity. While several elegant methods have so far been developed for GST activity assay [5, 6], these methods are limited by the expensive materials, sophisticated instruments, or their time-consuming experimental procedures. As a consequence, a facile, cheap, and sensitive method for GST activity assay is still highly desired.

Because of their easy preparation, excellent biocompatibility, and unique optoelectronic properties, gold nanoparticles (AuNPs) have attracted increasing attention in many fields. The well-dispersed AuNP solution is red, whereas the aggregated AuNP solution appears a blue color. The color change induced by aggregation of AuNPs provides an ideal platform for colorimetric analysis [7]. The major advantage of AuNPbased colorimetric assay is that the molecular recognition event can be transformed into color change, which can be easily observed by the naked eye, and therefore, no sophisticated instruments are required. AuNP-based colorimetric assay has been used for the detection of various substances including small molecules, DNA, and proteins [7-9]. The relatively simple measurement, inexpensive instrumentation, and robustness and potential for high-throughput assay make AuNP-based colorimetric assays excellent candidates for in vitro measurements of enzyme activity. There are already a number of AuNP-based colorimetric assays for transferases 
Scheme 1 Visual detection of GST activity based on the color change of $(+)$ AuNPs

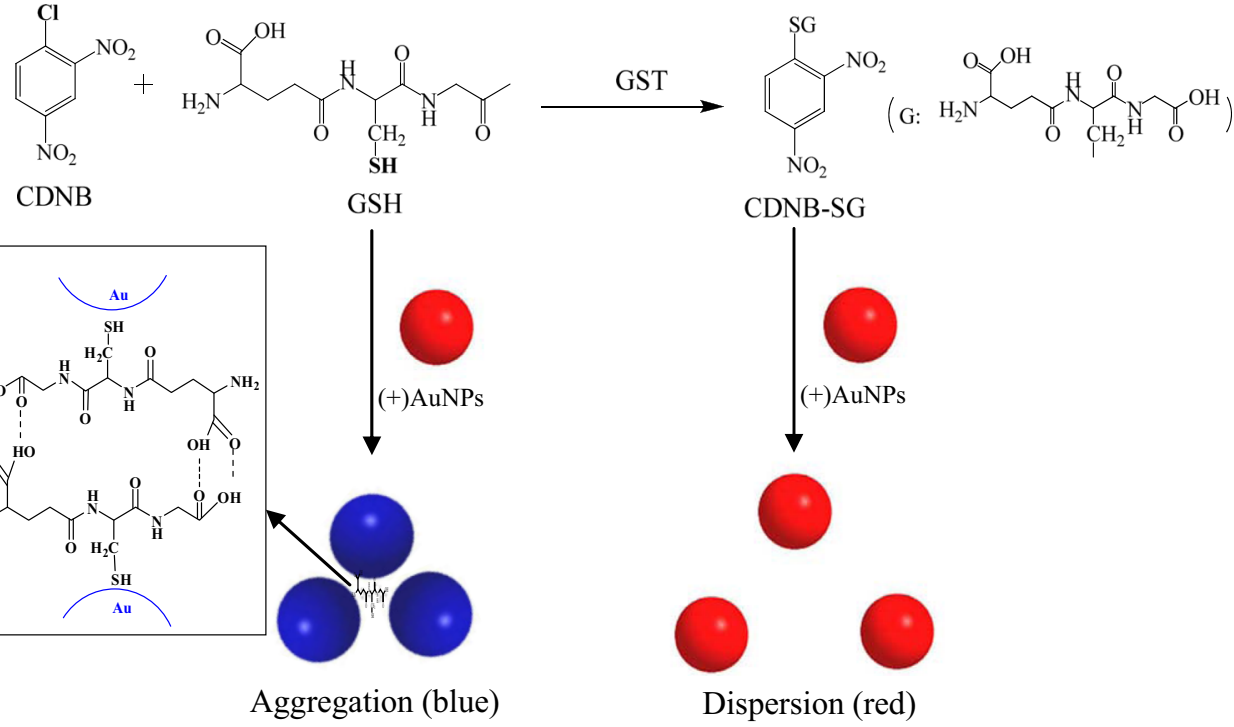

and hydrolases [10-16]. However, to the best our knowledge, AuNP-based colorimetric assay is not used to detect GST activity.

In this study, we propose one AuNP-based colorimetric assay for GST activity. The overall strategy is illustrated in Scheme 1. The cysteamine-capped AuNPs were synthesized and used as probes. GSH is the GST substrate, and GST can catalyze the reaction of CDNB and GSH to produce a conjugate (CDNB-SG). Thiol group of GSH tends to readily adsorb onto the surface colloidal particles via $\mathrm{Au}-\mathrm{S}$ bond, and then, GSH can induce aggregation of the AuNPs. As a result, the color of AuNP solution changes from red to blue. In the presence of GST, GSH is converted into CDNB-SG, and the AuNP solution remains red. Thus, GST activity can be facilely assayed with the naked eye or a simple colorimetric reader. Moreover, the colorimetric method developed here is also employed for GST inhibitor evaluation.

\section{Experimental}

\section{Reagents and chemical}

Chloroauric acid $\left(\mathrm{HAuCl}_{4}\right), \mathrm{GST}, \mathrm{GSH}, \mathrm{CDNB}$, dihydroquercetin, and sodium borohydride were purchased from Shanghai Chemical Reagent Company (Shanghai, China). Cysteamine was purchased from Sinopharm Chemical Reagent Company (Beijing, China). All other solvents and reagents in this investigation were of analytical grade and used without further purification. Millipore water $(18 \mathrm{M} \Omega \mathrm{cm})$ was used in all experiments. The experiments were conducted at room temperature $\left(\right.$ ca. $20^{\circ} \mathrm{C}$ ).

\section{Apparatus}

UV-visible adsorption spectra were recorded on a U-3900H UV-Vis Spectrophotometer (Hitachi, Japan) at room temperature using a $500-\mu \mathrm{L}$ black-body quartz curette with $1-\mathrm{cm}$ path length. The photographs were taken with a Cannon 500 digital camera. The $\mathrm{pH}$ measurements were carried out on model PB-10 digital ion analyzer (Sartorius Scientific Instruments Co., Ltd., China, Beijing). Transmission electron microscopy (TEM) measurements were made on a JEM-2100 transmission electron microscope (Jeol Co. Ltd., Japan). The samples for TEM characterization were prepared by placing a drop of colloidal solution on carbon-coated copper grid and dried at room temperature.

\section{Preparation of cysteamine-capped AuNPs}

All glassware used in the following procedure was cleaned in a bath of freshly prepared 3:1 $\mathrm{HNO}_{3} / \mathrm{HCl}$, rinsed thoroughly in water and dried in air prior to use. The positively charged AuNPs were prepared according to the published protocol [17]. Briefly, a cysteamine solution $(400 \mu \mathrm{L}, 213 \mathrm{mM})$ was added to $40 \mathrm{~mL}$ of $1.42 \mathrm{mM} \mathrm{HAuCl}_{4}$ solution. After stirring for $20 \mathrm{~min}$ at room temperature, $10 \mu \mathrm{L}$ of $10 \mathrm{mM} \mathrm{NaBH}_{4}$ solution was added, and the mixture was vigorously stirred for $10 \mathrm{~min}$ at room temperature in the dark. Then, the mixture was further stirred $15 \mathrm{~min}$, and the resulting win-red solution was stored in the refrigerator $\left(4{ }^{\circ} \mathrm{C}\right)$ and ready for use. The asprepared AuNPs were charactered with UV-visible absorption spectra and TEM. The results of TEM showed that the average size of the AuNPs was about $34 \mathrm{~nm}$. The concentration of the AuNP solution was $10.5 \mathrm{nM}$, which was estimated by the original concentration of the gold solution [18]. 


\section{Colorimetric detection of GST activity}

A typical colorimetric assay of GST was realized by following the procedure given in Scheme 1. First, to a 1.5-mL Eppendorf tube were added $25 \mu \mathrm{L}$ of GSH (12 mM), $45 \mu \mathrm{L}$ of CDNB (3.0 mM), $50 \mu \mathrm{L}$ of GST (appropriate concentration), and $200 \mu \mathrm{L}$ of triethanolamine-HCl buffer $(20 \mathrm{mM}, \mathrm{pH} 6.5)$, and then, the mixed solution was incubated for $60 \mathrm{~min}$ at $25{ }^{\circ} \mathrm{C}$. Second, $50 \mu \mathrm{L}$ of the reacted solution, $180 \mu \mathrm{L}$ of AuNPs (10.5 nM), $180 \mu \mathrm{L}$ of Britton-Robinson (BR) buffer (0.04 $\mathrm{M} \mathrm{H}_{3} \mathrm{PO}_{4}, 0.04 \mathrm{M} \mathrm{HAc}, 0.04 \mathrm{M} \mathrm{H}_{3} \mathrm{BO}_{3}$, pH 3.6), and $90 \mu \mathrm{L}$ of $\mathrm{H}_{2} \mathrm{O}$ were orderly added into a 1.5 -mL Eppendorf tube, and the solution was allowed to react for $15 \mathrm{~min}$ at room temperature (ca. $20^{\circ} \mathrm{C}$ ). Finally, the picture was taken, and the UV/Vis spectra were recorded. The control assays contained no enzyme and were performed under the above conditions.

\section{Results and discussion}

The cysteamine-capped AuNPs were synthesized by sodium borohydride reduction of hydrogen tetrachloroaurate(III) in the presence of cysteamine [17]. Because of the $-\mathrm{NH}_{3}{ }^{+}$group of cysteamine, the cysteamine-capped AuNPs are positively charged at low $\mathrm{pH}$. The positive-charged AuNPs $((+)$ AuNPs $)$ solution is stabilized against aggregation due to the positive capping agent's electrostatic repulsion between AuNPs [11]. The AuNPs were characterized by UV-Vis spectroscopy and TEM. The absorption spectrum of the AuNP solution showed a peak at $520 \mathrm{~nm}$ and appeared red (Fig. 1). The TEM images (Fig. 2) showed that the AuNPs were spherical in shape and nearly monodispersed with an average diameter of $34 \mathrm{~nm}$.

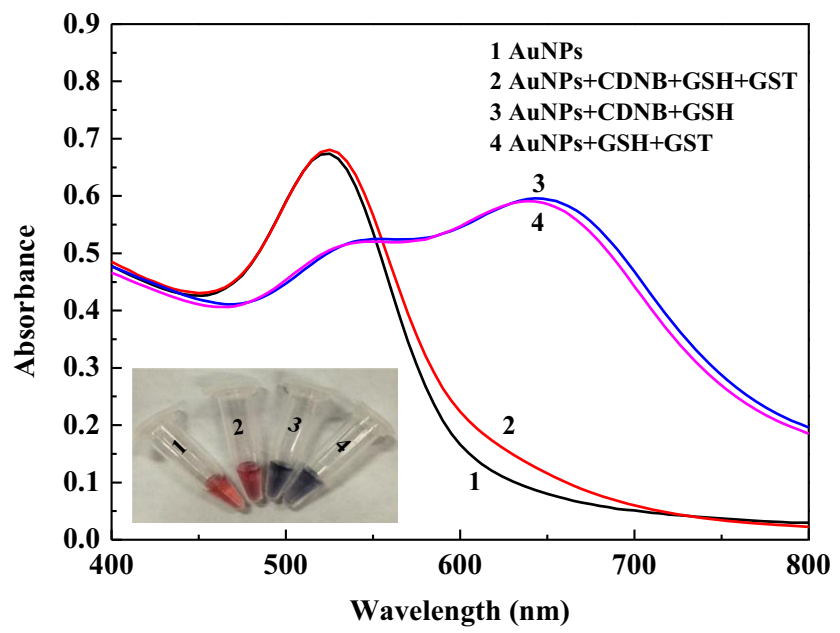

Fig. 1 Absorption spectra of the AuNPs (1), AuNPs-CDNB-GSH-GST (2), AuNPs-CDNB-GSH (3), and AuNPs-GSH-GST (4). The inset shows the corresponding photographs. Experimental conditions: GST, $0.3 \mathrm{U} / \mathrm{mL} ; C D N B, 3.0 \mathrm{mM}$; GSH, $2.5 \mathrm{mM}$; (+)AuNPs, $180 \mu \mathrm{L} ; B R$ buffer, pH 3.6, $200 \mu \mathrm{L}$

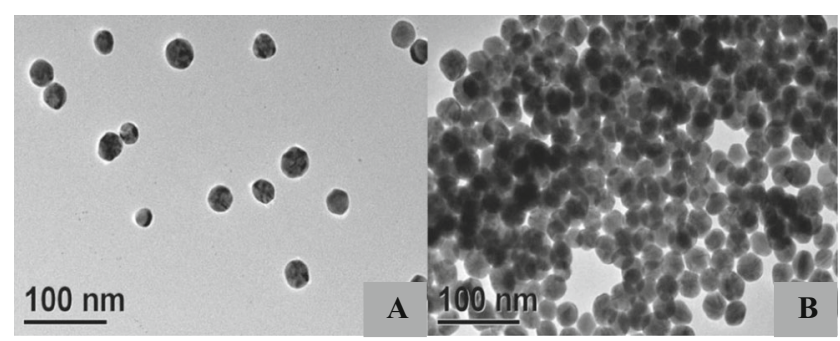

Fig. 2 TEM images of AuNPs-CDNB-GSH in the presence (a) and the absence (b) of GST. Experimental conditions: GST, $0.3 \mathrm{U} / \mathrm{mL}$; $C D N B$, 3.0 mM; GSH, 2.5 mM; (+)AuNPs, $180 \mu \mathrm{L} ;$ BR buffer, $\mathrm{pH} 3.6,200 \mu \mathrm{L}$

In order to verify the feasibility of the AuNP-based colorimetric assay for GST activity in the Scheme 1, the UV-Vis absorption spectra of the AuNP solution were measured in the presence and the absence of GST (Fig. 1). Curve 1 in Fig. 1 displays the absorption peak at $520 \mathrm{~nm}$, clearly indicating that AuNPs are dispersed under the reaction media. When GSH and CDNB were added into the AuNPs, a noticeable decrease at $520 \mathrm{~nm}$ and a significant increase at $670 \mathrm{~nm}$ in AuNP absorption spectra were observed (curve 3 ). This typical change of $A_{670} / A_{520}$ has been assigned to AuNP aggregation [11, 19]. In the absence of GST, GSH-CDNB could induce aggregation of AuNPs, and a significant color change from red to blue occurred. However, in the presence of GST, the aggregation of the AuNPs would not take place and the red-to-blue color change would not be observed. The changes in solution color and absorption spectra of the AuNPs thus allow one to probe GST activity.

To explore the mechanism of AuNP aggregation in this system, GSH, GST, and CDNB were added into the AuNP solution, respectively. The absorbance spectra and the solution color showed that GSH could induce the AuNP aggregation, and GST or CDNS itself did not cause AuNP aggregation. Furthermore, in order to know the microstructure of the AuNPs-CDNB-GSH without and with GST, the TEM images (Fig. 2) were obtained. Note that in the presence of GST, the AuNPs were monodispersed, while in the absence of GST, the AuNPs aggregated together. The TEM results gave the direct evidence for GSH-induced aggregation. The TEM results were consistent with the changes in solution color and absorption spectra. The thiol group exhibits intriguing reactivity with AuNPs [20]. GSH binds onto the gold surface through thiol group. Two - $\mathrm{COOH}$ groups of GSH have a $\mathrm{p} K_{\mathrm{a}}$ of 2.05 and 3.40, respectively [21]. Both the carboxylic acid groups of GSH can form intermolecular hydrogen bonding at $\mathrm{pH}<4.5$ [22]. The media $\mathrm{pH}$ in this system was 3.6. Thus, as depicted in Scheme 1, hydrogen bonding interaction between neighboring $-\mathrm{COOH}$ groups overcome the interparticle repulsive force (electrostatic and/or steric repulsion) and draw AuNPs to aggregate. In the presence of GST, GSH would conjugate CDNB through thiol group. There is no thiol group $(-\mathrm{SH})$ in the conjugate product (CDNB-SG) molecule, and the conjugate product cannot bind onto the surface of AuNPs 
through $\mathrm{Au}-\mathrm{S}$ bond. Thus, the conjugate product cannot induce the aggregation of AuNPs.

Furthermore, we prepared the citrate-capped AuNPs (ca.13 and $20 \mathrm{~nm}$ ) for the comparison study, and the zeta potential of the citrate-capped AuNPs was negative at $\mathrm{pH}$ 3.6. Experimental results showed that the GSH could not lead to the aggregation of the negatively charged AuNPs. At $\mathrm{pH}$ 3.6, the main molecular form of GSH is the anion ( $\mathrm{p} K_{\mathrm{a}}$ of 2.05 and 3.40). The anionic GSH does not easily interact with anionic citratecapped AuNPs because of electrostatic repulsion, and thus, GSH cannot induce the aggregation of citrate-capped AuNPs. However, the cysteamine-capped AuNPs are positively charged at $\mathrm{pH} 3.6$, and the electrostatic attraction between GSH and cysteamine-capped AuNPs would help to bind GSH on the AuNPs.

To improve the performance of GST activity assay, we optimized the experimental conditions. The effect of the amount of AuNPs was examined in the range 90-240 $\mu \mathrm{L}$. The experimental results (Fig. 3a) showed that the highest sensitivity was obtained when using $200 \mu \mathrm{L}$ AuNPs (10.5 nM). When $200 \mu \mathrm{L}$ of $\mathrm{pH} 3.6 \mathrm{BR}$ buffer solution $(0.04 \mathrm{M})$ was used as the reaction medium for GSH and AuNPs, the highest absorption ratio $\left(A_{670} / A_{520}\right)$ was obtained (Fig. 3b, c). The interaction between AuNPs and GSH was rather rapid, and a binding time of $15 \mathrm{~min}$ was enough at room temperature (Fig. 3d). In this work, $25 \mu \mathrm{L} \mathrm{GSH}(2.5 \mathrm{mM})$ and $45 \mu \mathrm{L} \mathrm{CDNB}(3.0 \mathrm{mM})$ were used as the substrate of the enzyme reaction, and $\mathrm{pH} 6.5$ Tris- $\mathrm{HCl}(20 \mathrm{mM})$ buffer was used as the enzyme reaction media.

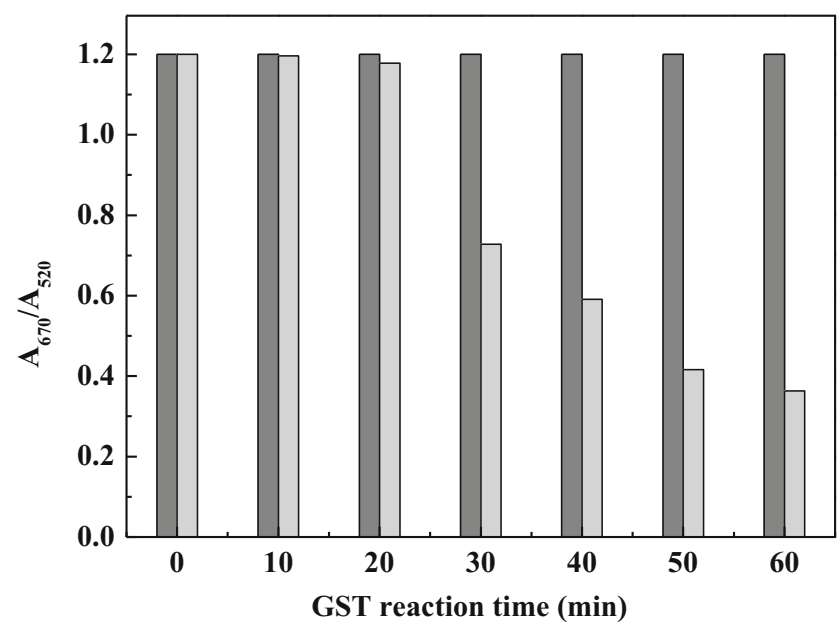

Fig. 4 Time-dependent $A_{670} / A_{520}$ absorbance ratio as a function of enzyme reaction time: blank (black) and $0.4 \mathrm{U} / \mathrm{mL}$ GST (gray). Experimental conditions: $C D N B, 3.0 \mathrm{mM}$; GSH, $2.5 \mathrm{mM}$; (+)AuNPs, $180 \mu \mathrm{L} ;$ BR buffer, $\mathrm{pH} 3.6,200 \mu \mathrm{L}$

Under the optimized conditions, AuNPs was used as probe to monitor the enzyme reaction process. A reaction mixture containing GSH and GST in Tris-HCl buffer ( $\mathrm{pH}$ 6.5) was incubated at $30{ }^{\circ} \mathrm{C}$ for $1 \mathrm{~h}$. The enzymatic reaction was stopped every $10 \mathrm{~min}$ by inactivation using boiling water. The reaction solution was added to the AuNPs, and then, the absorption spectra were measured. The absorbance of AuNPs at $520 \mathrm{~nm}$ gradually increased, and the absorbance at $670 \mathrm{~nm}$ gradually decreased with the incubating time from 0 to $60 \mathrm{~min}$. As shown in Fig. 4, the $A_{670} / A_{520}$ ratio of the reaction
Fig. 3 a Effect of AuNP amount on the absorption ratio $\left(A_{670}\right)$ $\left.A_{520}\right)$. Experimental conditions: $C D N B, 3.0 \mathrm{mM}$; GSH, $2.5 \mathrm{mM}$; BR buffer, $\mathrm{pH} 4.0,180 \mu \mathrm{L} ; A u N P$ binding time, $30 \mathrm{~min}$. b Effect of media $\mathrm{pH}$ on the absorption ratio. Experimental conditions: $C D N B$, $3.0 \mathrm{mM}$; GSH, $2.5 \mathrm{mM}$; (+ )AuNPs, $180 \mu \mathrm{L} ;$ BR buffer, $180 \mu \mathrm{L} ;$ AuNP binding time, 30 min. c Effect of buffer volume on the absorption ratio.

Experimental conditions: $C D N B$, $3.0 \mathrm{mM}$; GSH, $2.5 \mathrm{mM}$; (+ )AuNPs, $180 \mu \mathrm{L} ;$ BR buffer, $\mathrm{pH}$ 3.6; AuNP binding time, $30 \mathrm{~min}$. d Effect of binding time of GSH on the absorption ratio.

Experimental conditions: $C D N B$, $3.0 \mathrm{mM}$; GSH, $2.5 \mathrm{mM}$; (+ )AuNPs, $180 \mu \mathrm{L} ;$ BR buffer, $\mathrm{pH}$ 3.6, $200 \mu \mathrm{L}$
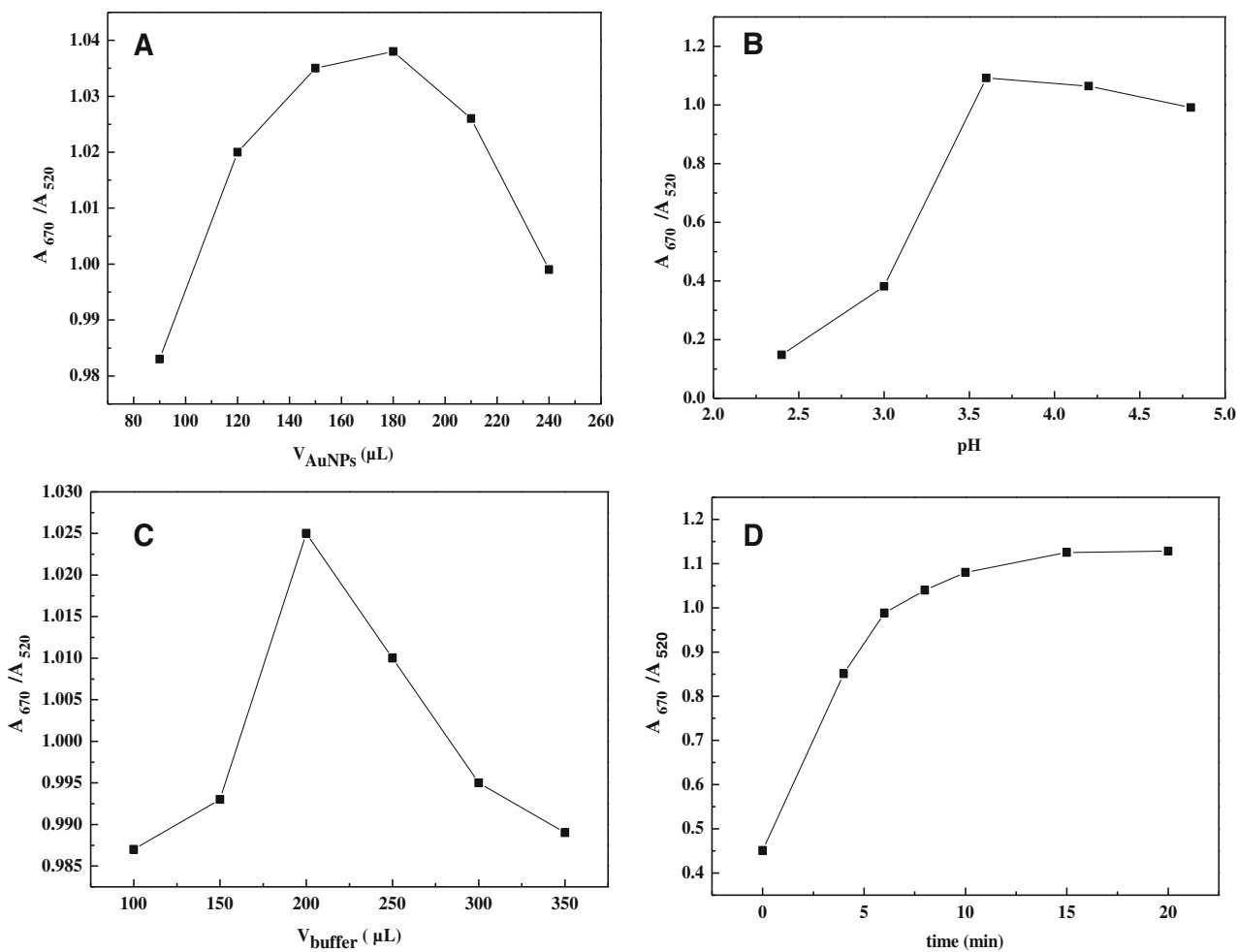


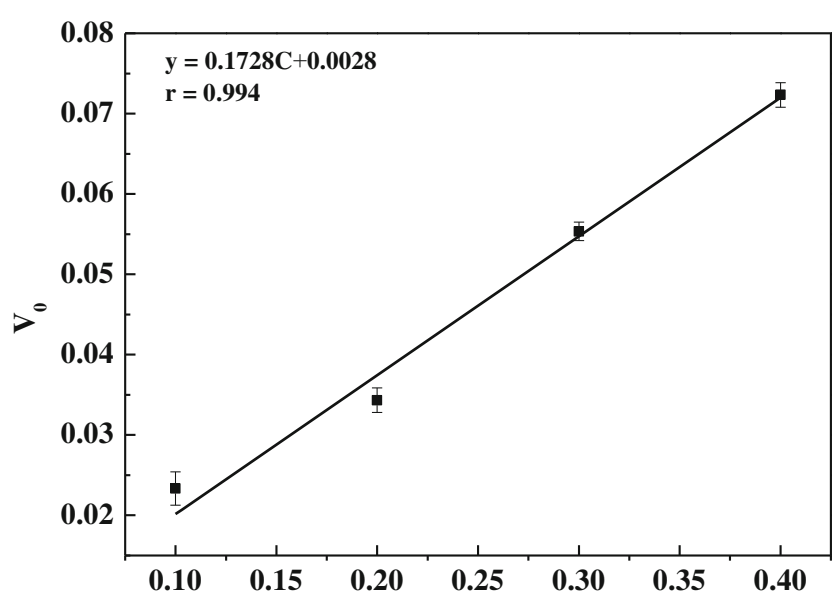

Glutathione-S-transferase concentration $(\mathrm{U} / \mathrm{mL})$

Fig. 5 Linear relation between the initial rate of enzyme reaction and enzyme activity. Experimental conditions: $C D N B, 3.0 \mathrm{mM}$; $G S H$, 2.5 mM; (+)AuNPs, $180 \mu \mathrm{L} ;$ BR buffer, pH 3.6, $200 \mu \mathrm{L}$

system decreased with increasing incubation time form 0 to $60 \mathrm{~min}$. The $A_{670} / A_{520}$ ratio of the system did not decrease any more after $60 \mathrm{~min}$, which indicated that the enzyme reaction was nearly completed within $1 \mathrm{~h}$ under the condition.

When the concentrations of GSH and CDNB substrate were fixed, the enzyme reaction rate is dependent on the concentration of the used GST. Five concentrations of GSH (0, $0.1,0.2,0.3$, and $0.4 \mathrm{U} / \mathrm{mL}$ ) were prepared to react with $\mathrm{GSH}-$ CDNB solution. The enzyme reaction was followed by measuring the absorption spectrum of AuNPs with the reaction mixture. The experimental results showed that the absorbance ratio rapidly decreased for the enzyme reaction with a high concentration of GST. The initial enzyme reaction rate $\left(V_{0}\right)$ was estimated from the absorbance ratio of the mixture before and after reaction of $10 \mathrm{~min}$, and a nearly linear plot of $V_{0}$ versus the concentration of GST was observed (Fig. 5). These results also validate the possibility of using the AuNPs as a colorimetric probe for GST activity. These results validate the possibility of using the AuNPs as colorimetric probe for GST activity. The enzymatic activity in the range $0.1-0.4 \mathrm{U} / \mathrm{mL}$ can be measured using a simple colorimetric reader. The detection limit that is taken to be three times the standard derivation in blank solution is found to be $0.06 \mathrm{U} / \mathrm{mL}$. Furthermore, the semi-quantitative analysis of GST activity could be performed

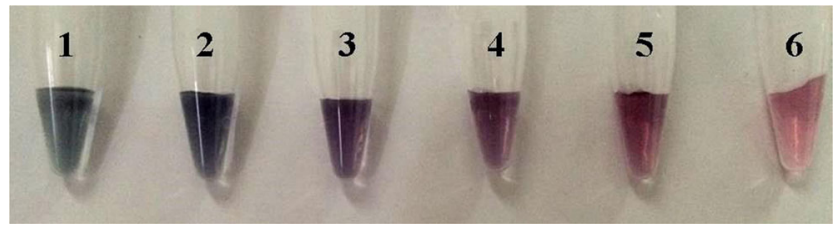

Fig. 6 Photographs of the reaction system in different conditions: $(1)$ blank, (2) $0.3 \mathrm{U} / \mathrm{mL}$ GST, (3) $0.4 \mathrm{U} / \mathrm{mL}$ GST, (4) $0.6 \mathrm{U} / \mathrm{mL}$ GST, (5) $0.8 \mathrm{U} / \mathrm{mL}$ GST, and (6) $1.0 \mathrm{U} / \mathrm{mL}$ GST. Experimental conditions: $3.0 \mathrm{mM}$ CDNB, $45 \mu \mathrm{L} ; 2.5 \mathrm{mM}$ GSH, $25 \mu \mathrm{L} ; 20 \mathrm{mM}$ Tris-HCl, $200 \mu \mathrm{L}$; (+ )AuNPs, $50 \mu \mathrm{L}$; pH 3.6 BR buffer solution, $100 \mu \mathrm{L}$; AuNP binding time, $15 \mathrm{~min}$ with the naked eye using $(+)$ AuNPs as colorimetric probes. From Fig. 6, it can be seen that the proposed method can allow the naked eye detection of GST in the range of $0.3 \sim 0.8 \mathrm{U} / \mathrm{mL}$ without resorting to any spectroscopic instrumentation. Compared with the method in the common GST assay method, this method is simple and easily operated.

GST can be used as targets for cancer therapy [2]. Molecules that inhibit GST are therefore considered candidates for new anticancer drug [23]. The GST-catalyzed GSH-CDNB reaction can be followed with AuNPs as colorimetric probes, and one can easily use the $A_{670} / A_{520}$ ratio to evaluate whether the molecule can inhibit GST activity and compare the inhibition efficiency among different inhibitors. Dihydroquercetin, a known GST inhibitor [24], was used in our proof-of-concept experiment. A certain amount of dihydroquercetin was added to the substrate solution before the enzyme reaction. As shown in Fig. 7, with increasing dihydroquercetin concentration, an obvious decrease in the absorption peak at $520 \mathrm{~nm}$ and a strong increase in the absorption peak at $670 \mathrm{~nm}$ were observed. Dihydroquercetin $(0.26 \mu \mathrm{M})$ could inhibit half of GST activity. The control experiments indicated that dihydroquercetin itself could not result in the spectra change of the AuNPs. In addition, the color of the AuNP solution gradually changed from its initial red color to blue (Fig. 7, inset). The color change of the AuNP solution can reveal experimental results more conveniently, and the color-based assay can be more easily operated. Hypochlorous acid is also the potent inhibitor of GST [25]. We studied the inhibition efficiency of hypochlorous acid with different concentrations, and $10 \mu \mathrm{M}$ hypochlorous acid could inhibit half of GST activity. At the same time, ascorbic acid was used as a model negative compound. The results showed that ascorbic acid could not change the absorption ratio of $A_{670} /$

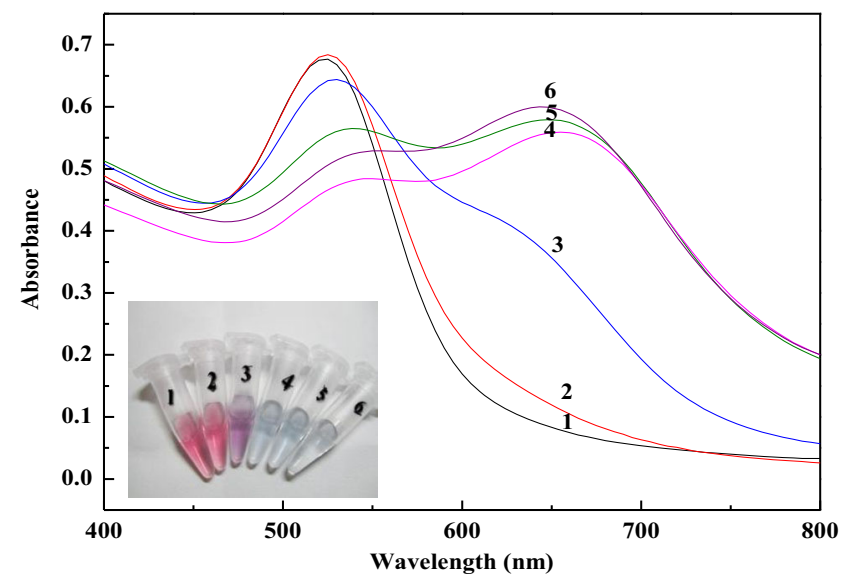

Fig. 7 Absorbance spectra of different systems: (1) AuNPs, (2) AuNPs + $\mathrm{CDNB}+\mathrm{GSH}+\mathrm{GST}$, (3) AuNPs + CDNB + GSH + GST + dihydroquercetin $(0.1 \mu \mathrm{M})$, (4) AuNPs + CDNB + GSH + GST + dihydroquercetin $(1.0 \mu \mathrm{M}),(5)$ AuNPs + CDNB + GSH + GST + dihydroquercetin $(10.0 \mu \mathrm{M})$, and $(6)$ AuNPs + CDNB + GSH. The inset shows the corresponding photographs. Experimental conditions: GST, $0.3 \mathrm{U} / \mathrm{mL}$; CDNB, $3.0 \mathrm{mM}$; GSH, $2.5 \mathrm{mM}$; (+)AuNPs, $180 \mu \mathrm{L}$; BR buffer, pH 3.6, $200 \mu \mathrm{L}$ 
$A_{520}$. These results of the inhibition assay also confirm the results for the GST activity.

\section{Conclusions}

In conclusion, a new colorimetric assay was developed for detecting GST activity. The assay is based on GSH-induced aggregation of cysteamine-capped AuNPs. The most important characteristic of the assay is direct visualization of the GST activity by the "naked eye", which makes it more convenient than other methods that rely on advanced instrumentation. The method is homogeneous, making it easy to automate by standard robotic manipulation of microwell plates. So, this simple and easily operated method can be adapted to high-throughput screening of GST inhibitors (potential drug candidates) from large combinatorial libraries.

Acknowledgments This work was supported financially by the National Natural Science Foundation of China (Nos. 21275096 and 21475083), Shaanxi Provincial Natural Science Foundation (No. 2013SZS08-Z01), and Program for Innovative Research Team in Shaanxi Province (No. 2014KCT-28).

Open Access This article is distributed under the terms of the Creative Commons Attribution 4.0 International License (http:// creativecommons.org/licenses/by/4.0/), which permits unrestricted use, distribution, and reproduction in any medium, provided you give appropriate credit to the original author(s) and the source, provide a link to the Creative Commons license, and indicate if changes were made.

\section{References}

1. Laborde E (2010) Glutathione transferases as mediators of signaling pathways involved in cell proliferation and cell death. Cell Death Differ 17:1373-1380. doi:10.1038/cdd.2010.80

2. Ruzza P, Rosato A, Rossi CR, Floreani M, Quintieri L (2009) Glutathione transferases as targets for cancer therapy. Anti Cancer Agents Med Chem 9:763-777. doi:10.2174/187152009789056895

3. Zhao GS, Wang XB (2006) Advance in antitumor agents targeting glutathione-S-transferase. Curr Med Chem 13:1461-1471. doi:10. 2174/092986706776872934

4. Habig WH, Pabst MJ, Jakoby WB (1974) Glutathione S-transferases: the first enzymatic step in mercapturic acid formation. J Biol Chem 249:7130-7139

5. Lu J, Song Y, Shi W, Li X, Ma H (2013)3, 4-Dinitrobenzamide functionalized $\mathrm{CdTe} / \mathrm{ZnTe}$ quantum dots as a nanoprobe for imaging glutathione S-transferase in living cells. Chin J Chem 31:472478. doi:10.1002/cjoc. 201300061

6. ZhouW, Shultz JW, Murphy N, Hawkins EM, Bernad L, Good T, Moothart L, Frackman S, Klaubert DH, Bulleit RF, Wood KV (2006) Electrophilic aromatic substituted luciferins as bioluminescent probes for glutathione S-transferase assays. Chem Commun 4620-4622. doi:10.1039/B610682J

7. Zhao W, Brook MA, Li Y (2008) Design of gold nanoparticlebased colorimetric biosensing assays. ChemBioChem 9:23632371. doi:10.1002/cbic.200800282
8. Saha K, Agasti SS, Kim C, Li X, Rotello VM (2012) Gold nanoparticles in chemical and biological sensing. Chem Rev 112:27392779. doi:10.1021/cr2001178

9. Xia F, Zuo X, Yang R, Xiao Y, Kang D, Vallée-Bélisle A, Gong X, Yuen JD, Hsu BBY, Heeger AJ, Plaxco KW (2010) Colorimetric detection of DNA, small molecules, proteins, and ions using unmodified gold nanoparticles and conjugated polyelectrolytes. PNAS 107:10837-10841. doi:10.1073/pnas.1005632107

10. Hutter E, Maysinger D (2013) Gold-nanoparticle-based biosensors for detection of enzyme activity. Trends Pharmacol Sci 34:497507. doi:10.1016/j.tips.2013.07.002

11. Ren S, Li B, Zhang L (2013) Visual detection of hexokinase activity and inhibition with positively charged gold nanoparticles as colorimetric probes. Analyst 138:3142-3145. doi:10.1039/c3an36528j

12. Zhen Z, Tang LJ, Long H, Jiang JH (2012) Enzymatic immunoassembly of gold nanoparticles for visualized activity screening of histone-modifying enzymes. Anal Chem 84:3614-3620. doi:10. $1021 / \mathrm{ac} 203385 \mathrm{v}$

13. Deng J, Jiang Q, Wang Y, Yang L, Yu P, Mao L (2013) Real-time colorimetric assay of inorganic pyrophosphatase activity based on reversibly competitive coordination of $\mathrm{Cu}^{2+}$ between cysteine and pyrophosphate ion. Anal Chem 85:9409-9415. doi:10.1021/ac402524e

14. Zhang L, Zhao J, Jiang J, Yu R (2012) Enzyme-regulated unmodified gold nanoparticle aggregation: a label free colorimetric assay for rapid and sensitive detection of adenosine deaminase activity and inhibition. Chem Commun 48:10996-10998. doi:10.1039/ $\mathrm{C} 2 \mathrm{CC} 36240 \mathrm{~F}$

15. Pan Y, Guo M, Nie Z, Huang Y, Peng Y, Liu A, Qing M, Yao S (2012) Colorimetric detection of apoptosis based on caspase-3 activity assay using unmodified gold nanoparticles. Chem Commun 48:997-999. doi:10.1039/C1CC15407A

16. Park SY, Kwon D, Mok H, Chung BH (2013) Simple and rapid detection of L-Dopa decarboxylase activity using gold nanoparticles. Analyst 138:3146-3149. doi:10.1039/C3AN00009E

17. Niidome T, Nakashima K, Takahashi H, Niidome Y (2004) Preparation of primary amine-modified gold nanoparticles and their transfection ability into cultivated cells. Chem Commmun 19781979. doi:10.1039/B406189F

18. Neiman B, Grushka E, Lev O (2001) Use of gold nanoparticles to enhance capillary electrophoresis. Anal Chem 73:5220-5227. doi: 10.1021/ac0104375

19. Guo Y, Zhang Y, Shao H, Wang Z, Wang X, Jiang X (2014) Label-free colorimetric detection of cadmium ions in rice samples using gold nanoparticles. Anal Chem 86:8530-8534. doi:10.1021/ac502461r

20. Li L, Li B (2009) Sensitive and selective detection of cysteine using gold nanoparticles as colorimetric probes. Analyst 134:1361-1365. doi:10.1039/B819842J

21. Rabenstein DL (1973) Nuclear magnetic resonance studies of the acid-base chemistry of amino acids and peptides. I. Microscopic ionization constants of glutathione and methylmercury-complexed glutathione. J Am Chem Soc 95:2797-2803. doi:10.1021/ ja00790a009

22. Lim I-IS, Mott D, Ip W, Njoki PN, Pan Y, Zhou S, Zhong C-J (2008) Interparticle interactions in glutathione mediated assembly of gold nanoparticles. Langmuir 24:8857-8863. doi:10.1021/la800970p

23. Materon EM, Huang P-JJ, Wong A, Ferreira AAP, Sotomayor MDPT, Liu J (2014) Glutathione-s-transferase modified electrodes for detecting anticancer drugs. Biosens Bioelectron 58:232-236. doi:10.1016/j.bios.2014.02.070

24. Li SJ, Zhang DQ, Dong YS (2004) Study on the high throughput screening model for the GST inhibitors. Chin J Antibiot 29:264 266. doi:10.13461/j.cnki.cja.003499

25. van Haaften R, den Hartog GJ, Evelo CT, Haenen GR, Bast A (2001) Hypochlorous acid is a potent inhibitor of GST P1-1. Chem Biol Interact 138:77-83. doi:10.1016/S0009-2797(01) 00262-9 